\title{
EL ÍNDICE DE CALIDAD DEL EMPLEO EN BOLIVIA Y SUS COMPONENTES
}

Julio Alvaro Salazar Aramayo

\section{RESUMEN}

El presente trabajo de investigación presenta el cálculo del Índice Multidimensional de Calidad del Empleo para Bolivia basado en método Alkire-Foster de doble conteo para medir privaciones traslapadas. Como base de datos se emplean las Encuestas de Hogares de las gestiones 2011 a 2019, realizadas por el Instituto Nacional de Estadística. Se determina que en promedio, el 69.18\% de la población de ocupados cuentan con empleos de mala calidad durante todo el periodo de estudio, y tienen una privación media en el $67.52 \%$ de las tres dimensiones consideradas para la modelación: Ingresos, Estabilidad laboral y Condiciones de Empleo con sus respectivas subdimensiones. Asimismo, se muestra que el valor del índice se puede atribuir en $40 \%$ al aporte de la dimensión de Ingresos, que muestra que el $58 \%$ de la población ocupada gana igual o menos de dos salarios mínimos nacionales. El 23\% del valor del índice se debe al tipo de contrato que firman los trabajadores, de los cuales el $64 \%$ no cuentan con un contrato dentro de su actual empleo. Finalmente, el 11\% se atribuye a la falta de acceso a los fondos de pensiones por parte del $62 \%$ de la población ocupada dentro de sus actuales empleos.

Palabras Clave: Índice Multidimensional, Calidad de Empleo, Privación, Población Ocupada.

DOI: 10.23881/idupbo.021.2-1e 